\title{
Classification of the height and flexibility of the medial longitudinal arch of the foot
}

\author{
Mette Kjærgaard Nilsson ${ }^{1 *+}$, Rikke Friis ${ }^{2 \dagger}$, Maria Skjoldahl Michaelsen ${ }^{3+}$, Patrick Abildgaard Jakobsen ${ }^{4 \dagger}$ and \\ Rasmus Oestergaard Nielsen ${ }^{5 \dagger}$
}

\begin{abstract}
Background: The risk of developing injuries during standing work may vary between persons with different foot types. High arched and low arched feet, as well as rigid and flexible feet, are considered to have different injury profiles, while those with normal arches may sustain fewer injuries. However, the cut-off values for maximum values (subtalar position during weight-bearing) and range of motion (ROM) values (difference between subtalar neutral and subtalar resting position in a weight-bearing condition) for the medial longitudinal arch (MLA) are largely unknown. The purpose of this study was to identify cut-off values for maximum values and ROM of the MLA of the foot during static tests and to identify factors influencing foot posture.
\end{abstract}

Methods: The participants consisted of 254 volunteers from Central and Northern Denmark (198 m/56 f; age 39.0 \pm 11.7 years; BMI $27.3 \pm 4.7 \mathrm{~kg} / \mathrm{m}^{2}$ ). Navicular height $(\mathrm{NH})$, longitudinal arch angle (LAA) and Feiss line (FL) were measured for either the left or the right foot in a subtalar neutral position and subtalar resting position. Maximum values and ROM were calculated for each test. The $95 \%$ and $68 \%$ prediction intervals were used as cut-off limits. Multiple regression analysis was used to detect influencing factors on foot posture.

Results: The 68\% cut-off values for maximum MLA values and MLA ROM for NH were 3.6 to $5.5 \mathrm{~cm}$ and 0.6 to 1.8 $\mathrm{cm}$, respectively, without taking into account the influence of other variables. Normal maximum LAA values were between 131 and $152^{\circ}$ and normal LAA ROM was between -1 and $13^{\circ}$. Normal maximum FL values were between -2.6 and $-1.2 \mathrm{~cm}$ and normal FL ROM was between -0.1 and $0.9 \mathrm{~cm}$. Results from the multivariate linear regression revealed an association between foot size with $\mathrm{FL}, \mathrm{LAA}$, and navicular drop.

Conclusions: The cut-off values presented in this study can be used to categorize people performing standing work into groups of different foot arch types. The results of this study are important for investigating a possible link between arch height and arch movement and the development of injuries.

Keywords: Medial longitudinal arch, Longitudinal arch angle, Navicular drop, Feiss line

\section{Background}

The structure and the movements of the foot arches are crucial for a person's wellbeing and for optimal function of the body [1]. Because the medial longitudinal arch (MLA) is the primary shock-absorbing structure of the foot, this area of the foot is particularly important for foot function [2]. To date, no firm conclusions can be made on the link between midfoot posture and the development of injuries. Finch [3] suggested conducting

\footnotetext{
* Correspondence: mkn1986@hotmail.com

+ Contributed equally

${ }^{1}$ Clinic of Physical Therapy and Training, Ikast, Denmark

Full list of author information is available at the end of the article
}

large scale prospective studies to investigate if the time to injury differs between individuals with different midfoot postures. In such a prospective cohort study, participants must be categorized into exposure groups based on their midfoot posture at baseline. Then, participants are followed over time to identify if the hazard of sustaining an injury varies among persons with different foot postures. However, to our knowledge no cut-off values have been presented to categorize participants into exposure groups based on their midfoot posture.

In general, two different approaches have been used to quantify midfoot characteristics. In the first approach, the maximum value is measured, which represents the

\section{Biomed Central}


maximal deformation of the MLA in a weight-bearing condition. In the second approach, the range of motion (ROM) is measured, which is the difference between the subtalar joint neutral position and the subtalar joint resting position measured in a weight-bearing position [4]. Different tests have been proposed to measure maximum values and ROM of the MLA. First, in 1909, the Feiss line (FL) was described [5], which classified foot type in the subtalar joint neutral and the subtalar joint resting positions. Second, navicular height $(\mathrm{NH})$ and navicular drop (ND) were described by Brody in 1982 [6]. These methods allowed measurement, and evaluation, of the amount of pronation and its significance. Finally, in 1991 the longitudinal arch angle (LAA) was presented by Dahle et al. [7] to determine the relationship between foot type with subsequent knee pain or ankle sprains and to establish the interrater reliability of classifying foot type by visual observation. Because all three methods can be used to quantify the maximum value and ROM of MLA, cut-off values to categorize MLA into high arched, normal, and low arched should be provided for all three tests.

Previously, Williams et al. [8] used the standard deviation of the mean value to define cut-off values for the arch index of the midfoot, a fourth method used to quantify midfoot maximum values and ROM. Based on the cut-off values for the arch ratios, participants were divided into groups. Williams et al. [8] reported that a low or a high arch structure was associated with different injury patterns. In previous studies, participants have been categorized into exposure groups based on their alignment of other parts of the lower extremity [9]. Similarly, it is possible to categorize participants into exposure groups based on the static assessments of the $\mathrm{NH}$ [6], LAA [7], and FL [5]. However, to date the cutoff values for $\mathrm{NH}, \mathrm{LAA}$, and FL have only been reported as expert statements [6] or based on visual assessment [7]. To our knowledge, there is no report of using the prediction intervals to define cut-off values for $\mathrm{NH}$, LAA, and FL. The primary purpose of this study was to identify cut-off values for maximum values and ROM values of $\mathrm{NH}, \mathrm{LAA}$, and FL based on the $68 \%$ and $95 \%$ prediction intervals.

While foot size and gender have been shown to be associated with measures of the midfoot in dynamic conditions, body mass index (BMI) or age do not appear to be associated with $\mathrm{NH}$ under dynamic measures [10]. However, to date it is unclear if these variables would be associated with foot posture in static measures. Furthermore, the total number of years of performing standing work and the number of hours worked at the time of measurement may be associated with the foot measures. The secondary purpose of this study was to determine the association between foot size, gender,
BMI, age, years of performing standing work and hours worked at the time of measurement with $\mathrm{NH}$, LAA, and $\mathrm{FL}$, and if these parameters play a role to present a method to calculate cut-off values taking into account the association between different variables with $\mathrm{NH}$, LAA, and FL.

\section{Methods \\ Participants}

Thirteen different companies in Jutland, Denmark, were contacted and asked if their employees who regularly perform standing work would participate in the study. Eight companies agreed to take part in the study, and their employees were asked to participate during their working hours. The sample population consisted of adult citizens from Central and Northern Denmark who were able to stand with their subtalar joint in neutral position. Informed written consent was obtained from each participant prior to the measurements. Overall, 258 men and women agreed to participate. Four participants were excluded because of data loss. Hence, data for 254 volunteers aged 18 to 68 years were included in the study.

\section{Procedures}

The measurements were conducted by four clinicians. First, the clinician measured the participant's height, weight and foot length. A ruler (Folding rule, Probuilder, ABS Plastic) was used to measure foot length from the most posterior aspect of calcaneus to the tip of the longest toe. Then, the participant filled out a questionnaire about various clinical and demographic variables including age, gender, and injury history. Subsequently, the participant was placed standing barefoot on both feet with the subtalar joint in subtalar neutral position. Neutral position of the subtalar joint was defined as equal palpation of the medial and lateral aspects of the head of talus in relation to the navicular [10]. The following anatomical landmarks were identified by palpation and marked with a pen (CD/DVD marker, Relief); the centre of the medial malleolus, the navicular tuberosity, and the head of the first metatarsal bone. From these landmarks the maximum values of $\mathrm{NH}$ [6], LAA [11], and FL were measured for both feet with the subtalar joint in neutral position. Finally the participants were asked to relax, and NH, LAA, and FL were measured in the subtalar resting position. The differences between the measurements of NH, LAA, and FL with the subtalar joint in neutral position and measurements with the subtalar joint in the resting position were defined as ROM values for each test, respectively.

$N H$ : The perpendicular distance between the floor and the navicular tuberosity was measured with a ruler (Figure 1). Sell et al. [12] reported an ICC ranging from 


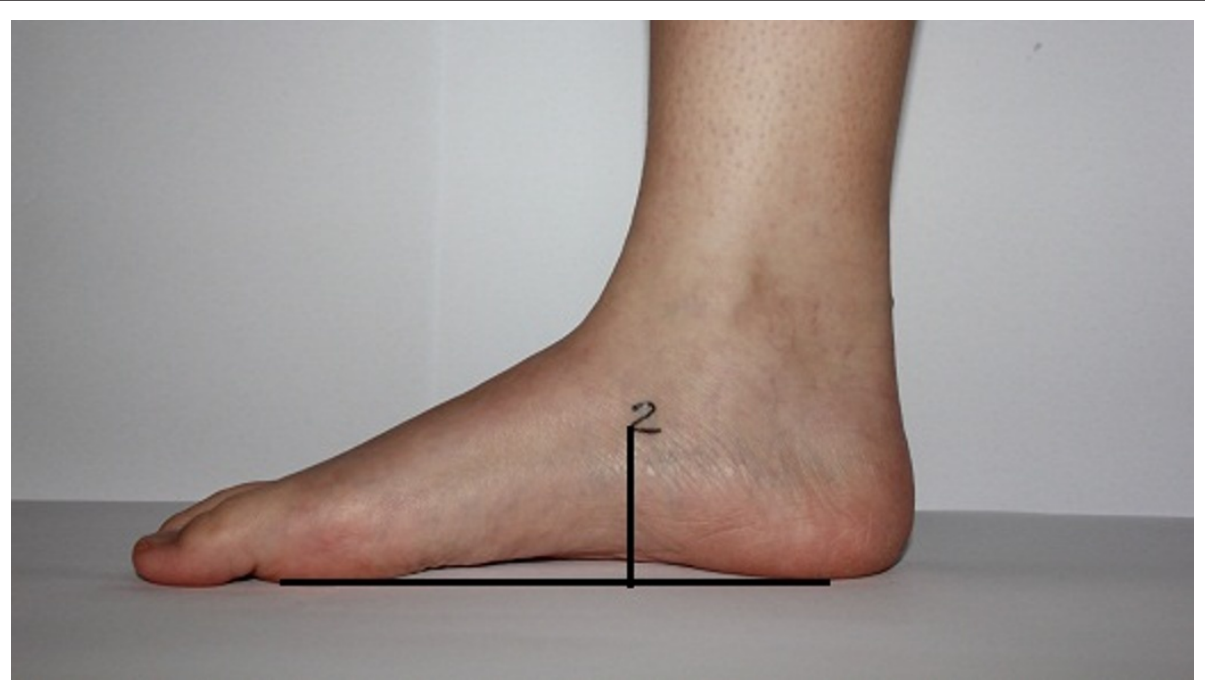

Figure 1 Navicular height with the foot in subtalar neutral position. The foot was in the subtalar neutral position and landmark 2 (navicular tuberosity) was used to measure the navicular height and the navicular drop. With the foot in a weightbearing position the measurements were repeated, and navicular tuberosity was marked again.

0.73 to 0.96 for the intertester and intratester reliability. Menz et al. [13] found NH to be significantly associated with the corresponding radiographic measure (Pearson $\mathrm{r}$ $=0.79$ ).

LAA: The centre of the goniometer (ProTerapi A/S) was placed at the navicular tuberosity, and the ends of the goniometer followed the landmarks on the centre of medial malleolus and the head of the first metatarsal. The angle (LAA) between the line from the medial malleolus to the navicular tuberosity and the line connecting the head of the first metatarsal bone and the navicular tuberosity was measured in degrees (Figure 2). Dahle et al. [7] reported a Kappa value for intertester reliability of 0.72 for visually assessing LAA, and Jonson et al. [14] reported an intratester and intertester ICC of 0.90 and 0.81 , respectively.

$F L$ : A line was drawn between the centre of the medial malleolus and the head of the first metatarsal bone. Then, a ruler $(15 \mathrm{~cm}$, Relief) was used to measure the perpendicular distance in centimeters between the navicular tuberosity and the line from the medial malleolus to the head of the first metatarsal bone (Figure 3). If the navicular tuberosity was above the line, the measured distance was positive. If the navicular tuberosity was below the line, the value was negative. There are currently no studies showing the reliability of this test.

\section{Statistics}

Significant differences between the right and left foot were found for LAA $(p=0.002)$ and FL $(p=0.035)$. However, these differences between right and left foot did not change the cut-off values significantly. Therefore, the differences were considered clinically insignificant. By pooling data from right and left foot, the assumption of independence is violated [15]. Therefore, data from either the right or the left foot was randomly included in the analysis. Descriptive data were presented as counts and percentage for dichotomous data, and as mean, standard deviation and 95\% confidence interval for continuous data. All continuous data were normally distributed, tested by histograms and probability plots. Therefore, \pm 1 standard deviation from the mean (68\% prediction interval) were used as maximum value cut-off limits between normal and low arched and between normal and high arched feet. The ROM cut-off values between normal and flexible and between normal and rigid feet were calculated correspondingly. Furthermore, \pm 2 standard deviations from the mean (95\% prediction interval) were used as maximum value cut-off limits between low arched and severely low arched feet and between high arched and severely high arched feet. A corresponding approach was used for the ROM cut-off limits. Multivariate linear regression analysis was used to test the associated between age, BMI, foot length, years performing standing work and hours worked at the time of measurement with the measures of the medial longitudinal arch in male and female participants, respectively. The direction of the relationships was hypothesized to be positive for foot length and negative between NL, LAA, and FL and the covariates included in the analysis. Because no significant differences in LAA, FL, and NH measurements were found between healthy and previously injured participants, the data was not stratified based on injury status. All statistical tests were carried out in STATA (Texas, USA) version IC 11.0. 


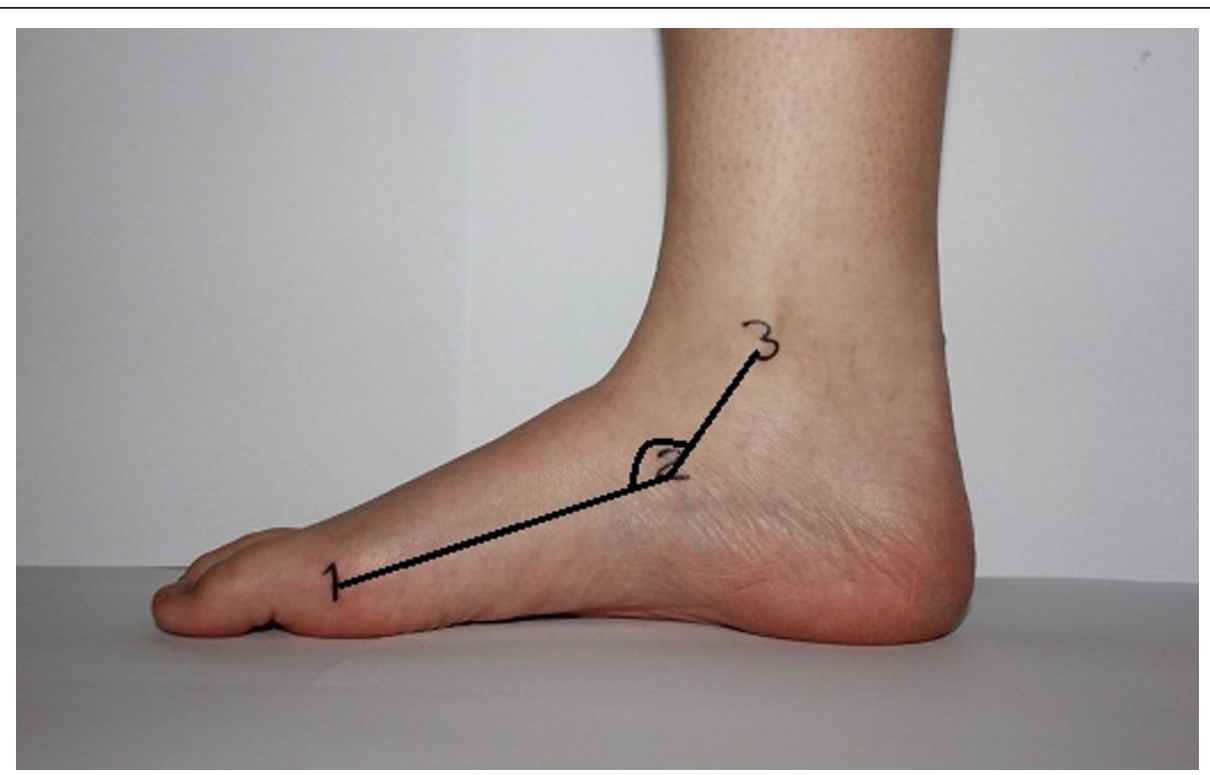

Figure 2 Longitudinal arch angle with the foot in subtalar neutral position. The foot was in its subtalar neutral position and the landmarks (1-3) were used to measure LAA. 1 head of first metatarsal bone; 2 navicular tuberosity; and 3 centre of the medial malleolus. A line was drawn from landmark 1 to 2 and from landmark 2 to 3 . The superior angle between line 1 to 2 and line 2 to 3 was measured in degrees. With the foot in a weightbearing position, the measurements were repeated and the navicular tuberosity was marked again.

\section{Results}

\section{Demographic characteristics}

The demographic characteristics of the 254 participants of this study are presented in Table 1.
Mean, standard deviation, 95\% confidence interval and range for LAA, NH, and FL measurements are presented in Table 2.

Mean $( \pm 1 \mathrm{SD})$ maximum values for NH, LAA, and FL were $4.6 \mathrm{~cm}(0.9 \mathrm{~cm}), 141.8 \mathrm{~cm}(10.4 \mathrm{~cm})$, and $-1.9^{\circ}$

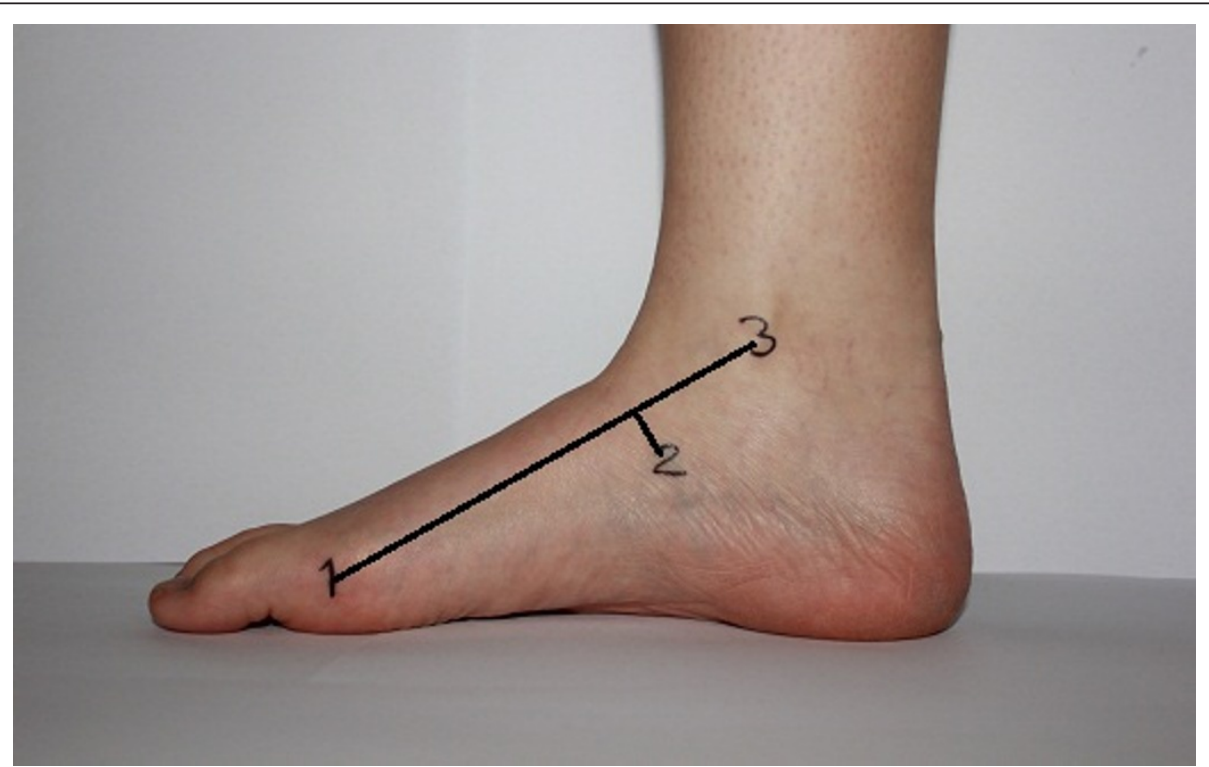

Figure 3 Feiss line with the foot in subtalar neutral position. The foot was in its subtalar neutral position and the landmarks (1-3) are used to measure Feiss line. 1 head of first metatarsal bone; 2 navicular tuberosity; and 3 centre of the medial malleolus. A line between landmark 1 and 3 was drawn and the perpendicular distance between landmark 2 and line 1 to 3 was measured. With the foot in a weightbearing position, the measurements were repeated, and the navicular tuberosity was marked again. 
Table 1 Demographic characteristics

\begin{tabular}{|c|c|c|c|c|}
\hline Variable & Mean & SD & $95 \% \mathrm{Cl}$ & Range \\
\hline Age (years) & 39 & 11.7 & 37 to 40 & 18 to 64 \\
\hline $\mathrm{BMI} \mathrm{kg} / \mathrm{m}^{2}$ & 27.3 & 4.7 & 26.7 to 27.9 & 18.2 to 44.0 \\
\hline Sex* & $198 \mathrm{~m} / 56 \mathrm{f}$ & N/A & N/A & N/A \\
\hline Previous injuries during the last 12 months (yes $/ \mathrm{no})^{*}$ & $40 / 214$ & N/A & N/A & N/A \\
\hline Standing work (years) & 19 & 11.8 & 17.6 to 20.5 & 1 to 50 \\
\hline Standing work today (min) & 259 & 114 & 244 to 273 & 0 to 720 \\
\hline Foot size $(\mathrm{cm})$ & 26.3 & 1.7 & 26.1 to 26.4 & 22 to 30.3 \\
\hline
\end{tabular}

Demographic characteristics of the participants $(n=254)$. SD: standard deviation; $95 \% \mathrm{Cl}$ : $95 \%$ confidence intervals; $\mathrm{cm}$ : centimetre; min: minutes; ${ }^{*}$ proportion presented. Standing work years represents the total number of years performing standing work. Standing work today represents the number of hours worked at the time of measurement. N/A = not available

$\left(0.7^{\circ}\right)$, respectively. Without taking into account the effect of other variables, the $68 \%$ and $95 \%$ prediction limits for maximum values and ROM for ND, LAA, and FL are presented in Table 3.

Normal maximum MLA and MLA ROM were for $\mathrm{NH}$ between 3.6 and $5.5 \mathrm{~cm}$ and between 0.6 and $1.8 \mathrm{~cm}$, respectively. For LAA normal maximum values were between 131 and $152^{\circ}$ and normal ROM values were between -1 and $13^{\circ}$. Normal maximum FL values were between -1.2 and $-2.6 \mathrm{~cm}$ and normal FL ROM values were between -0.1 and $0.9 \mathrm{~cm}$. These values represent the $68 \%$ prediction limits.

\section{Multivariate linear regression analysis}

Results from the multivariate linear regression analysis testing the association between foot length, BMI, age, work performed on the day of testing, and number of year performing standing work with the different measures of MLA are presented in Table 4.

Table 2 Mean, SD, $95 \% \mathrm{Cl}$, and range of the test parameters

\begin{tabular}{ccccc}
\hline \multicolumn{5}{c}{ Maximum values } \\
$\mathbf{n}=\mathbf{2 5 4}$ \\
\hline Test & Mean & SD & $\mathbf{9 5 \% ~} \mathbf{~ I ~}$ & Range \\
\hline NH $(\mathrm{cm})$ & 4.6 & 0.9 & 4.4 to 4.7 & 2.0 to 7.2 \\
\hline FL $(\mathrm{cm})$ & -1.9 & 0.7 & -2.0 to -1.8 & -4.0 to 2.2 \\
\hline LAA $\left(^{\circ}\right)$ & 142 & 10.4 & 141 to 143 & 114 to 172 \\
\hline \multicolumn{5}{c}{ Range of motion values } \\
$\mathbf{n}=\mathbf{2 5 4}$ \\
\hline Test & Mean & SD & $\mathbf{9 5 \% ~ C l}$ & Range \\
\hline ND $(\mathrm{cm})$ & 1.2 & 0.6 & 1.1 to 1.3 & -0.3 to 3.2 \\
\hline FL $(\mathrm{cm})$ & 0.4 & 0.5 & 0.3 to 0.5 & -3.8 to 2.3 \\
\hline LAA $\left(^{\circ}\right)$ & 6 & 7 & 5 to 7 & -15 to 26 \\
\hline
\end{tabular}

Mean, standard deviation (SD), 95\% confidence intervals (95\% Cl), and range between minimum and maximum values for navicular height $(\mathrm{NH})$, navicular drop (ND), Feiss line (FL) and longitudinal arch angle (LAA). Maximum values represent the foot in its weight-bearing position. Range of motion represents the difference between subtalar neutral position and subtalar resting position with both feet in a weight bearing condition
Age only had a significant association with maximum LAA values among males. Among males, foot length was associated with ND and maximum LAA and FL. Work performed on the day of testing, BMI and number of years performing standing work had little or no association with midfoot measures. The regression equation used to calculate the normalized range for the tests taken into account other covariates was

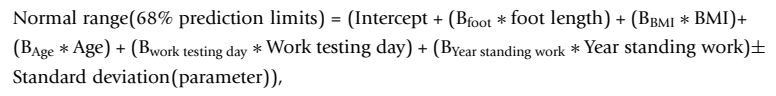

where work testing day was the number of hours of work performed on the day of testing and year standing work was the number of years performing standing work.

\section{Discussion}

The primary purpose of this study was to identify cutoff values for maximum and ROM values of $\mathrm{NH}$, LAA and FL based on the $68 \%$ and $95 \%$ prediction intervals. Cut-off values for maximum values or ROM in the static assessment of FL, NH, and LAA were presented without taking into account the effect of other variables. These cut-off values can be used by clinicians as a simple tool to categorize the MLA of persons who perform standing work. Furthermore, multivariate regression analysis was used to calculate cut-off values while taking into account foot size and other parameters.

Categorization of MLA can be calculated based on the regression equation and $68 \%$ and $95 \%$ cut-off values using the standard deviation reported in Table 2: cut off value (regression equation) \pm ( 1 or 2 standard deviations). For instance the $68 \%$ cut-off values/normal reference range for ND for a 30-year old male with a foot length of $28 \mathrm{~cm}$, BMI of $25 \mathrm{~kg} / \mathrm{m}^{2}$ who has been working 4 hours at the time of measurement and worked 4 years performing standing work are:

$(-0.67+(0.07 * 28)+(-0.01 * 25)+(-0.003 * 30)+(-0.003 * 4)+(0.005 * 4)) \pm 0.6=0.5 \mathrm{~cm}$ to $1.7 \mathrm{~cm}$.

This equation represents a precise method for calculating the cut-off values. This method can be used in 
Table 3 Cut-off values for NH, FL and LAA

\begin{tabular}{|c|c|c|c|c|c|}
\hline \multicolumn{6}{|c|}{$\begin{array}{c}\text { Maximum values } \\
\mathrm{n}=254\end{array}$} \\
\hline Test & Severely low arch & Low arch & Normal & High arch & Severely high arch \\
\hline $\mathrm{NH}(\mathrm{cm})$ & $<2.7$ & 2.7 to 3.5 & 3.6 to 5.5 & 5.6 to 6.4 & $>6.4$ \\
\hline $\mathrm{FL}(\mathrm{cm})$ & $<-3.3$ & -3.3 to -2.5 & -2.6 to -1.2 & -1.3 to -0.4 & $>-0.4$ \\
\hline LAA $\left({ }^{\circ}\right)$ & $<121$ & 121 to 130 & 131 to 152 & 153 to 162 & $>162$ \\
\hline \multicolumn{6}{|c|}{$\begin{array}{l}\text { Range of motion values } \\
\qquad n=254\end{array}$} \\
\hline Test & Very flexible & Flexible & Normal & Rigid & Very rigid \\
\hline $\mathrm{ND}(\mathrm{cm})$ & $>2.3$ & 2.3 to 1.8 & 1.8 to 0.6 & 0.6 to 0.0 & $<0.0$ \\
\hline $\mathrm{FL}(\mathrm{cm})$ & $>1.3$ & 1.3 to 0.9 & 0.9 to -0.1 & -0.1 to -0.6 & $<-0.6$ \\
\hline $\operatorname{LAA}\left({ }^{\circ}\right)$ & $>19$ & 19 to 13 & 13 to -1 & -1 to -7 & $<-7$ \\
\hline
\end{tabular}

Cut-off values of the medial longitudinal arch maximum values and range of motion values without taking into account the association between the variables included in the regression models with $\mathrm{NH}, \mathrm{FL}$, and LAA. In relation to maximum values and range of motion values, the normal categories were defined by the $68 \%$ prediction limit cut-offs. Low arch and high arched feet as well as flexible and rigid feet were categorized based on the $95 \%$ prediction limit cut-offs. $\mathrm{NH}$ : navicular height; FL: Feiss line; LAA: Longitudinal arch angle

future studies categorize participants into groups based on their midfoot posture.

The results of this study can be compared with other studies. Brody [6] reported normal amounts of ND of approximately $1 \mathrm{~cm}$ and considered a value of $1.5 \mathrm{~cm}$ as the upper boundary limit while no lower boundary limit was reported. In the current study, a normal ND was within the range of 0.6 to $1.8 \mathrm{~cm}$, which corresponds well with the suggestions by Brody. However, it must be emphasized that the normal range of 0.6 to $1.8 \mathrm{~cm}$ was calculated without taking into account the effect of other variables.

To our knowledge, to date no cut-off values have been reported for NH. However, several studies [12,16-18] reported mean values of 3.7 to $4.7 \mathrm{~cm}$, which is within the range of 3.6 to $5.5 \mathrm{~cm}$ used in the current study to categorize a normal foot.

Previously, LAA has been assessed visually by Dahle et al. [7]. Based on results from 55 participants, LAAs between 120 and $150^{\circ}$ were classified as normal. The cut-off values of 131 to $152^{\circ}$ reported in the current study were close to the proposed values reported by Dahle et al. [7]. However, cut-off values of 162 and $121^{\circ}$ to distinguish between high arched and severely high arched and between low arched and severely low arched, respectively, differ considerably from those proposed by Dahle et al. [7] who suggested that participants with LAA close to $90^{\circ}$ were classified as low arched, while participants with an LAA close to $180^{\circ}$ were considered to have a high arch.

No studies were found which reported cut-off values or mean values for FL tests. Therefore, no external comparisons with the normal range of 0.9 to $-0.1 \mathrm{~cm}$ can be made.

The results of the multivariate linear regression analysis revealed that age only had an association with maximum LAA values among males. However, the change in estimate per year was rather small. Therefore, the association between age with maximum LAA values is considered clinically insignificant. This result is in contrast to previous findings where a U-shaped pattern was reported between age and foot posture among children, in the general population and in the elderly [19]. However, because neither children nor elderly people were included in the current study, the insignificant association between age with most midfoot measures may be explained by the different age groups included in the two studies.

No clinically relevant and, in most cases, no statistically significant association between BMI, hours of standing work before the measurements, and total years performing standing work were found from with the different measurements of the MLA. These results are similar to those of Nielsen et al. [10] who found that age and BMI had no significant association with the foot position in dynamic conditions. However, in three studies $[10,19,20]$, foot length was significantly associated with $\mathrm{NH}$. In the current study, foot size had a significant association with most MLA parameters among males. Per $1 \mathrm{~cm}$ increase in foot size, ND was increased by $0.7 \mathrm{~mm}$. For example, when comparing a $30 \mathrm{~cm}$ foot size with a $40 \mathrm{~cm}$ foot size, the expected increase in ND would be $0.7 \mathrm{~cm}$. To avoid misclassification, such association between foot size and ND should be considered when categorizing subjects into high arched, normal and low arched groups, taking into account that a normal ND is between 0.6 and $1.8 \mathrm{~cm}$. The effect of foot size can be accounted for by calculating the cut-off value based on the equation described above.

In the current study, NH, LAA, and FL were used to classify the midfoot posture in the sagittal plane. However, other tests for evaluating foot position have been described in the literature. 
Table 4 Association between other variables with $\mathrm{NH}$, FL, and LAA

\begin{tabular}{|c|c|c|c|c|c|c|}
\hline & \multicolumn{3}{|c|}{ Women $n=56$} & \multicolumn{3}{|c|}{ Men $n=198$} \\
\hline & B & SE & $P$ & B & SE & $P$ \\
\hline & \multicolumn{3}{|c|}{ Navicular height (MV) } & \multicolumn{3}{|c|}{ Navicular height (MV) } \\
\hline$r^{2}$ & \multicolumn{3}{|c|}{0.06} & \multicolumn{3}{|c|}{0.04} \\
\hline Intercept & 3.93 & \multicolumn{2}{|l|}{2.35} & 4.31 & \multicolumn{2}{|l|}{1.43} \\
\hline Foot length & 0.04 & 0.10 & 0.703 & -0.02 & 0.05 & 0.679 \\
\hline BMI & -0.012 & 0.02 & 0.556 & 0.01 & 0.02 & 0.501 \\
\hline Age & -0.02 & 0.02 & 0.169 & -0.01 & 0.01 & 0.492 \\
\hline Work today & 0.03 & 0.05 & 0.589 & 0.01 & 0.04 & 0.951 \\
\hline \multirow[t]{2}{*}{ Year stand } & 0.01 & 0.01 & 0.357 & -0.01 & 0.01 & 0.488 \\
\hline & \multicolumn{3}{|c|}{ Navicular drop (ROM) } & \multicolumn{3}{|c|}{ Navicular drop (ROM) } \\
\hline$r^{2}$ & \multicolumn{3}{|c|}{0.13} & \multicolumn{3}{|c|}{0.04} \\
\hline Intercept & 0.14 & 1.52 & & -0.67 & 0.92 & \\
\hline Foot length & 0.06 & 0.07 & 0.369 & 0.07 & 0.03 & 0.020 \\
\hline BMI & 0.01 & 0.01 & 0.733 & -0.01 & 0.01 & 0.528 \\
\hline Age & -0.01 & 0.01 & 0.789 & -0.01 & 0.01 & 0.967 \\
\hline Work today & -0.06 & 0.03 & 0.060 & -0.01 & 0.03 & 0.911 \\
\hline \multirow[t]{2}{*}{ Year stand } & -0.01 & 0.01 & 0.242 & 0.01 & 0.01 & 0.526 \\
\hline & \multicolumn{3}{|c|}{ FL (MV) } & \multicolumn{3}{|c|}{ FL (MV) } \\
\hline$r^{2}$ & \multicolumn{3}{|c|}{0.17} & \multicolumn{3}{|c|}{0.09} \\
\hline Intercept & 1.13 & 1.85 & & 1.83 & 1.14 & \\
\hline Foot length & -0.07 & 0.08 & 0.419 & -0.11 & 0.04 & 0.005 \\
\hline BMI & -0.02 & 0.02 & 0.143 & -0.01 & 0.01 & 0.729 \\
\hline Age & -0.02 & 0.01 & 0.051 & -0.01 & 0.01 & 0.196 \\
\hline Work today & -0.01 & 0.04 & 0.766 & -0.02 & 0.03 & 0.425 \\
\hline \multirow[t]{2}{*}{ Year stand } & 0.01 & 0.01 & 0.273 & 0.00 & 0.01 & 0.806 \\
\hline & \multicolumn{3}{|c|}{ FL (ROM) } & \multicolumn{3}{|c|}{ FL (ROM) } \\
\hline$r^{2}$ & \multicolumn{3}{|c|}{0.13} & \multicolumn{3}{|c|}{0.05} \\
\hline Intercept & 0.34 & 1.15 & & -0.12 & 0.78 & \\
\hline Foot length & -0.02 & 0.05 & 0.724 & -0.01 & 0.03 & 0.843 \\
\hline BMI & 0.01 & 0.01 & 0.296 & 0.01 & 0.01 & 0.051 \\
\hline Age & 0.02 & 0.01 & 0.051 & 0.00 & 0.01 & 0.997 \\
\hline Work today & -0.01 & 0.03 & 0.582 & 0.03 & 0.02 & 0.195 \\
\hline Year stand & -0.02 & 0.01 & 0.035 & -0.12 & 0.78 & 0.875 \\
\hline & & A (MV & & & A (M) & \\
\hline$r^{2}$ & & 0.12 & & & 0.11 & \\
\hline Intercept & 161.10 & 29.50 & & 183.30 & 15.50 & \\
\hline Foot length & -0.58 & 1.30 & 0.658 & -1.20 & 0.54 & 0.026 \\
\hline BMI & -0.01 & 0.25 & 0.967 & 0.24 & 0.16 & 0.133 \\
\hline Age & -0.34 & 0.19 & 0.077 & -0.34 & 0.13 & 0.008 \\
\hline Work today & 0.87 & 0.63 & 0.177 & -0.55 & 0.42 & 0.189 \\
\hline Year stand & 0.21 & 0.18 & 0.243 & 0.09 & 0.12 & 0.462 \\
\hline & & (RON & & & $A(\mathrm{RO})$ & \\
\hline$r^{2}$ & & 0.11 & & & 0.01 & \\
\hline Intercept & 20.79 & 20.06 & & 8.49 & 10.36 & \\
\hline Foot length & -0.61 & 0.88 & 0.494 & -0.02 & 0.36 & 0.960 \\
\hline
\end{tabular}

Table 4 Association between other variables with $\mathrm{NH}$, FL, and LAA (Continued)

\begin{tabular}{lllllll}
\hline BMl & -0.05 & 0.17 & 0.774 & -0.01 & 0.11 & 0.924 \\
\hline Age & 0.21 & 0.13 & 0.102 & -0.09 & 0.09 & 0.290 \\
\hline Work today & -0.17 & 0.43 & 0.699 & 0.06 & 0.28 & 0.817 \\
\hline Year stand & -0.30 & 0.12 & 0.018 & -0.06 & 0.08 & 0.448 \\
\hline
\end{tabular}

Multivariate linear regression analysis of the association between foot length $(\mathrm{cm}), \mathrm{BMI}\left(\mathrm{kg} / \mathrm{m}^{2}\right)$, age (years), hours worked at the time of measurement (work today), and total years with standing work (years standing) with maximum values (MV) and range of motion (ROM) in males and females, respectively. FL: Feiss line, LAA: Longitudinal arch angle. B coefficients with standard error were determined. $P$ values $<0.05$ were statistically significant for these analyses

Recently, the Foot Posture Index (FPI) has been shown to be a valid and reliable tool for performing multiple segment, multiple plane evaluation of the foot as a whole $[19,21,22]$. Both the quantification of the midfoot measured in a single segment and the evaluation of the FPI in multiple segments can be used as tools to investigate the relationship between foot postures and injury development. One item of the FPI is the visual assessment of the arch height and congruence. Visual assessment of the MLA is a fast and simple alternative to describing midfoot posture compared with the tests presented in the current article. However, in their review, Razeghi and Batt [23] found one study where foot type classification based on direct observation demonstrated significantly higher variability. In another study, Cowan et al. [24] found the probability of two clinicians assessing the same foot as clearly flat ranged from 0.32 to 0.79 , with a median probability of 0.57 , while for clearly high-arched feet, comparable probabilities ranged from 0.00 to 1.00 , with a median of 0.17 . Based on these findings, it was concluded that there is a need for objective standards and quantitative methods for evaluating the MLA. The question arises whether or not the visual assessment of MLA is an appropriate tool in the FPI when valid and reliable alternatives such as $\mathrm{NH}$ or LAA exist.

Future studies should investigate if NH or LAA provide a better estimate of the midfoot than visual assessment of MLA which is used in the FPI. If this is the case, one may consider creating an extended FPI model where the visual assessment of the MLA would be replaced by NH or LAA. The method for calculating the cut-off values presented in the current study could be used to differentiate between the five categories $(-2$ to +2 ) currently used in the FPI.

Based on the cut-off values presented in this study, future studies can be conducted to investigate the injury incidence in persons with severely high, high, normal, low and severely low arched feet. If injury incidence varies between individuals with different foot postures, 
specific treatment modalities for modifying foot position and/or reducing the injury incidence would be warranted.

This study has some limitations. First, a relatively small sample of women was included in this study. Therefore, results of the regression analysis based on data from the 56 females should be interpreted with caution. Second, neutral position of the subtalar joint was defined as equal palpation of the medial and lateral aspects of the head of talus in relation to the navicular [10]. Previously, Pierrynowski et al. [25] investigated the proficiency of students and clinicians to place the foot in subtalar neutral. They found the rearfoot angle measured by experienced foot care specialists to be measured within $+/-3.0^{\circ}$ of the subtalar neutral position $90 \%$ of the time. The corresponding value for the students was $+/-4.9^{\circ}$. Similarly, it has been stated that no method for measuring subtalar neutral position has been proven accurate and reproducible by different testers [26]. Therefore, the placement of the subtalar joint in its neutral position may be the greatest limitation in the current study. The ROM measurements presented may be interpreted with caution because the placement of the foot in subtalar neutral is part of the procedure for measuring the ROM.

\section{Conclusion}

An approach to calculate cut-off values for NH, LAA, and FL measurements based on regression equations and standard deviation has been presented. These cutoff values can be used to differentiate between maximum foot arch values and foot arch ROM in the sagittal plane in people who regularly perform standing work. Based on these results, new prospective studies can be designed to elucidate if there is a link between arch height and arch movement and the development of injuries.

\section{Non-financial competing interests}

There are no political, personal, religious, ideological, academic, intellectual, commercial or any other competing interests related to the content of the manuscript.

\footnotetext{
Abbreviations

ROM: Range of motion; MLA: Medial longitudinal arch; BMl: Body mass index; NH: Navicular height; LAA: Longitudinal arch angle; FL: Feiss line; ND: Navicular drop; SD: Standard deviation; Cl: Confidence intervals; Min: Minimum; Max: Maximum; cm: Centimeter; Min: Minutes; N/A: Not available; FPI: Foot Posture Index.
}

\section{Acknowledgements}

Dr. Med. Sten Rasmussen from the Orthopaedic Surgery Research Unit, Aalborg, Denmark is acknowledged for obtaining funding for salary for RON and contributed with materials essential for the study. Anne Mette K. Brødbæk from VIA University College, Holstebro is acknowledged for conception and feedback on design of the research.

\section{Author details}

${ }^{1}$ Clinic of Physical Therapy and Training, Ikast, Denmark. ${ }^{2}$ Department of Orthopaedics, Thy- Mors Center of Head, Orthopaedics and Heart, Aalborg Hospital, Aalborg, Denmark. ${ }^{3}$ Clinic of Physical Therapy and Training, Ulfborg, Denmark. ${ }^{4}$ VIA University College, Holstebro, Denmark. ${ }^{5}$ Orthopaedic Surgery Research Unit, The Head, Ortho and Heart Centre, Aarhus University Hospital, Aarhus, Denmark.

\section{Authors' contributions}

All authors read and approved the final manuscript. MKN carried out the acquisition of data and has been involved in drafting the manuscript. RF carried out the acquisition of data and has been involved in drafting the manuscript. MSM carried out the acquisition of data and has been involved in drafting the manuscript. PAJ carried out the acquisition of data and has been involved in drafting the manuscript. RON has made substantial contributions to conception, design, analysis, and interpretation of data as well as revised the manuscript critically for important intellectual content.

\section{Competing interests}

Financial competing interests

None of the authors hold any stocks or shares in an organization or have received reimbursements, fees, funding, or salary from an organization that may in any given way gain or lose financially from the publication of this manuscript, either now or in the future. None of the authors or organizations are currently applying for patents relating to the content of the manuscript.

Received: 22 May 2011 Accepted: 17 February 2012

Published: 17 February 2012

\section{References}

1. Fukano M, Fukubayashi T: Motion characteristics of the medial and lateral longitudinal arch during landing. Eur J Appl Physiol 2009, 105:387-392.

2. Oatis CA, Beattie PF: Kinesiology: The Mechanics and Pathomechanics of Human Movement. 2 edition. Philidelphia: Lippincott Williams \& Wilkins; 2009.

3. Finch C: A new framework for research leading to sports injury prevention. J Sci Med Sport 2006, 9:3-9, discussion 10.

4. Grau S, Maiwald C, Krauss I, Axmann D, Janssen P, Horstmann T: What are causes and treatment strategies for patellar-tendinopathy in female runners? J Biomech 2008, 41:2042-2046.

5. Feiss $\mathrm{HO}$ : A simple method of estimating the common variations and deformities of the foot. Am J Med Sci 1909, 138:230.

6. Brody DM: Techniques in the evaluation and treatment of the injured runner. Orthop Clin North Am 1982, 13:541-558.

7. Dahle LK, Mueller MJ, Delitto A, Diamond JE: Visual assessment of foot type and relationship of foot type to lower extremity injury. J Orthop Sports Phys Ther 1991, 14:70-74.

8. Williams DS III, McClay IS, Hamill J: Arch structure and injury patterns in runners. Clinic Biomech (Bristol, Avon) 2001, 16:341-347.

9. Rauh MJ, Koepsell TD, Rivara FP, Rice SG, Margherita AJ: Quadriceps angle and risk of injury among high school cross-country runners. J Orthop Sports Phys Ther 2007, 37:725-733.

10. Nielsen $\mathrm{RG}$, Rathleff MS, Simonsen $\mathrm{OH}$, Langberg $\mathrm{H}$ : Determination of normal values for navicular drop during walking: a new model correcting for foot length and gender. J Foot Ankle Res 2009, 2:12.

11. McPoil TG, Cornwall MW: Use of the longitudinal arch angle to predict dynamic foot posture in walking. J Am Podiatr Med Assoc 2005, 95:114-120.

12. Sell KE, Verity TM, Worrell TW, Pease BJ, Wigglesworth J: Two measurement techniques for assessing subtalar joint position: a reliability study. $J$ Orthop Sports Phys Ther 1994, 19:162-167.

13. Menz HB, Munteanu SE: Validity of 3 clinical techniques for the measurement of static foot posture in older people. J Orthop Sports Phys Ther 2005, 35:479-486.

14. Jonson SR, Gross MT: Intraexaminer reliability, interexaminer reliability, and mean values for nine lower extremity skeletal measures in healthy naval midshipmen. J Orthop Sports Phys Ther 1997, 25:253-263.

15. Menz HB: Two feet, or one person? Problems associated with statistical analysis of paired data in foot and ankle medicine. Foot 2004, 14:2-5. 
16. Bandholm T, Boysen L, Haugaard S, Zebis MK, Bencke J: Foot medial longitudinal-arch deformation during quiet standing and gait in subjects with medial tibial stress syndrome. J Foot Ankle Surg 2008, 47:89-95.

17. Cavanagh PR, Morag E, Boulton AJ, Young MJ, Deffner KT, Pammer SE: The relationship of static foot structure to dynamic foot function. $J$ Biomech 1997, 30:243-250.

18. Chu WC, Lee SH, Chu W, Wang TJ, Lee MC: The use of arch index to characterize arch height: a digital image processing approach. IEEE Trans Biomed Eng 1995, 42:1088-1093.

19. Redmond AC, Crane YZ, Menz HB: Normative values for the Foot Posture Index. J Foot Ankle Res 2008, 1:6.

20. Astrom M, Arvidson T: Alignment and joint motion in the normal foot. J Orthop Sports Phys Ther 1995, 22:216-222.

21. Redmond AC, Crosbie J, Ouvrier RA: Development and validation of a novel rating system for scoring standing foot posture: the Foot Posture Index. Clin Biomech (Bristol, Avon) 2006, 21:89-98.

22. Keenan AM, Redmond AC, Horton M, Conaghan PG, Tennant A: The Foot Posture Index: Rasch analysis of a novel, foot-specific outcome measure. Arch Phys Med Rehabil 2007, 88:88-93.

23. Razeghi M, Batt ME: Foot type classification: a critical review of current methods. Gait Posture 2002, 15:282-291

24. Cowan DN, Robinson JR, Jones BH, Polly DW Jr, Berrey BH: Consistency of visual assessments of arch height among clinicians. Foot Ankle Int 1994, 15:213-217.

25. Pierrynowski MR, Smith SB, Mlynarczyk JH: Proficiency of foot care specialists to place the rearfoot at subtalar neutral. $J$ Am Podiatr Med Assoc 1996, 86:217-223.

26. Chen YX, Yu GR, Mei J, Zhou JQ, Wang W: Assessment of subtalar joint neutral position: a cadaveric study. Chin Med J (Engl) 2008, 121:735-739.

doi:10.1186/1757-1146-5-3

Cite this article as: Nilsson et al:: Classification of the height and

flexibility of the medial longitudinal arch of the foot. Journal of Foot and Ankle Research 2012 5:3.

\section{Submit your next manuscript to BioMed Central and take full advantage of:}

- Convenient online submission

- Thorough peer review

- No space constraints or color figure charges

- Immediate publication on acceptance

- Inclusion in PubMed, CAS, Scopus and Google Scholar

- Research which is freely available for redistribution

Submit your manuscript at www.biomedcentral.com/submit 